\title{
Disruption of root carbon transport into forest humus stimulates fungal opportunists at the expense of mycorrhizal fungi
}

\author{
Björn D Lindahl ${ }^{1}$, Wietse de Boer ${ }^{2}$ and Roger D Finlay ${ }^{1}$ \\ ${ }^{1}$ Department of Forest Mycology and Pathology, Swedish University of Agricultural Sciences, Uppsala, \\ Sweden and ${ }^{2}$ Department of Terrestrial Microbial Ecology, Centre for Terrestrial Ecology, Netherlands \\ Institute of Ecology, Heteren, The Netherlands
}

\begin{abstract}
Ectomycorrhizal fungi dominate the humus layers of boreal forests. They depend on carbohydrates that are translocated through roots, via fungal mycelium to microsites in the soil, wherein they forage for nutrients. Mycorrhizal fungi are therefore sensitive to disruptive disturbances that may restrict their carbon supply. By disrupting root connections, we induced a sudden decline in mycorrhizal mycelial abundance and studied the consequent effects on growth and activity of free living, saprotrophic fungi and bacteria in pine forest humus, using molecular community analyses in combination with enzyme activity measurements. Ectomycorrhizal fungi had decreased in abundance 14 days after root severing, but the abundance of certain free-living ascomycetes was three times higher within 5 days of the disturbance compared with undisturbed controls. Root disruption also increased laccase production by an order of magnitude and cellulase production by a factor of 5 . In contrast, bacterial populations seemed little affected. The results indicate that access to an external carbon source enables mycorrhizal fungi to monopolise the humus, but disturbances may induce rapid growth of opportunistic saprotrophic fungi that presumably use the dying mycorrhizal mycelium. Studies of such functional shifts in fungal communities, induced by disturbance, may shed light on mechanisms behind nutrient retention and release in boreal forests. The results also highlight the fundamental problems associated with methods that study microbial processes in soil samples that have been isolated from living roots.
\end{abstract}

The ISME Journal (2010) 4, 872-881; doi:10.1038/ismej.2010.19; published online 11 March 2010

Subject Category: microbial population and community ecology

Keywords: competition; disturbance; ectomycorrhiza; extracellular enzymes; microbial communities

\section{Introduction}

Filamentous fungi are classified as microorganisms because of the microscopic diameter of their hyphae that enables them to penetrate microsites within different substrates. However, many fungi, especially basidiomycetes, produce mycelia that extend over decimetre to metre distances, through which they may translocate carbohydrates and nutrients over considerable distances (Finlay and Read, 1986; Boddy, 1999). Resource reallocation enables these fungi to mobilise resources locally at one place but to use them to support growth in other, distant parts of their mycelia (Lindahl and Olsson, 2004). Ectomycorrhizal fungi support dense hyphal networks by translocating recently photosynthesised carbohydrates from the roots of their host plants, ensuring

Correspondence: BD Lindahl, Department of Forest Mycology and Pathology, Swedish University of Agricultural Sciences, Box 7026, Uppsala SE-750 07, Sweden.

E-mail: Bjorn.Lindahl@mykopat.slu.se

Received 19 November 2009; revised 26 January 2010; accepted 26 January 2010; published online 11 March 2010 efficient nutrient assimilation in humus layers and mineral soils (Leake et al., 2001; Rosling et al., 2004). The dependency on translocation of photosynthetic products through roots and mycelia allows mycorrhizal fungi to act independently of locally available organic carbon in the soil, but at the same time makes them vulnerable to disruptive disturbances.

In the organic humus layers of coniferous forests, ectomycorrhizal species have been found to dominate fungal communities (O'Brien et al., 2005; Lindahl et al., 2007), and in laboratory microcosms, ectomycorrhizal fungi have been found to compete successfully with saprotrophs for soil space and nutrients (Lindahl et al., 1999, 2001, 2002; Werner et al., 2002). Being supported by carbohydrates from their host plants rather than depending on energy from organic matter, mycorrhizal fungi may exclude saprotrophs from energy-depleted substrates, to monopolise nutrients for themselves and their hosts (Lindahl et al., 2007). Under nutrient poor conditions, ectomycorrhizal fungi may also increase nutrient availability by producing extracellular enzymes (Lindahl et al., 2005), facilitating direct recycling of nutrients in organic forms (Lindahl 
et al., 2002; Read and Perez-Moreno, 2003). Such tight cycling of nutrients ultimately depends on intact translocation pathways between the photosynthesising leaves, via roots to the mycorrhizal mycelium colonising organic substrates in humus and soil.

Previous long-term studies of the effects of root disruption (Siira-Pietikäinen et al., 2001; Brant et al., 2006) or tree girdling (Högberg and Högberg, 2002; Subke et al., 2004) have all found marked decreases in fungal biomass, because of detrimental effects on mycorrhizal taxa (Yarwood et al., 2009). Physical disturbance of the microbial community in boreal forest soils also frequently results in release of $\mathrm{NH}_{4}^{+}$ (Yavitt and Fahey, 1984; Siira-Pietikäinen et al., 2001; Lavoie and Bradley, 2003; Piirainen et al., 2007), and elevated $\mathrm{NH}_{4}^{+}$levels have also been observed in association with repeated freeze-thaw cycles (Sulkava and Huhta, 2003) and clear-cutting (Carmosini et al., 2003; Lapointe et al., 2005). Increased N mineralisation after disturbance has been suggested to depend on a rapid turnover of dead microbial biomass (DeLuca et al., 1992). The transformation of disturbance-sensitive, ectomycorrhizal mycelium into a dead resource for opportunistic saprotrophs would involve complex interactions between different functional guilds of microorganisms, regarding which we still know very little.

Boreal forest soils may be described as relatively stable systems. Earthworms, acting to prevent the establishment of mycelial translocation pathways by soil mixing (Butenschoen et al., 2007), are rare in boreal forest soils. Although seasonal changes may be pronounced, the dominant plants are evergreen and degradation of litter components is extended over several years, ensuring a continuous supply of carbohydrates to soil microorganisms via roots and litter. We hypothesise that, in this otherwise stable environment, sudden disturbances may quickly shift the balance between different functional guilds of microorganisms, with large subsequent effects on ecosystem processes. To test whether disruption of mycorrhizal translocation pathways stimulates growth of free-living saprotrophs, we studied shortterm (14 days) responses of the microbial community to a sudden disturbance induced by the insertion of plastic tubes into forest humus, severing roots. Using DNA-based methods to target both fungi and bacteria, we monitored community changes at the level of species and functional groups. We also measured activities of extracellular enzymes involved in organic matter degradation.

\section{Materials and methods}

Sample collection

The field study was conducted in late September 2006 at Jädraås $\mathrm{IhV}\left(60^{\circ} 49^{\prime} \mathrm{N}, 16^{\circ} 30^{\prime} \mathrm{E}\right.$, altitude $185 \mathrm{~m}$ ), which is a well-documented field site in central Sweden (Persson, 1980; Lindahl et al., 2007).
The site consists of Pinus sylvestris L. forest with an understory of ericaceous dwarf shrubs (Vaccinium vitis-ideae L. and Calluna vulgaris (L.) Hull) and mosses (Pleurozium schreberi (Bridel) Mitten and Dicranum majus Turner), growing on a sandy podzol. Plastic tubes $(150 \mathrm{~mm}$ long, $28 \mathrm{~mm}$ diameter) with sharpened edges were pushed through the litter and humus layers down into the mineral soil, using a rubber hammer. In total, 25 tubes were inserted $1 \mathrm{~m}$ apart along a linear transect. After 5 days, every other core was retrieved together with control samples, taken along a parallel transect $1 \mathrm{~m}$ from the first one. The control tubes were hammered into the soil immediately before the cores were re-collected. The remaining cores were retrieved together with new control cores after a total of 14 days of incubation. Soil cores were sub-divided immediately; mineral soil, mosses and structurally intact litter were discarded and well-fragmented litter and humus was frozen on dry ice directly on sampling. While still frozen, the samples were crushed and roughly homogenised in a mortar and sub-divided for further analyses.

\section{Analyses}

Detailed descriptions of the analysis methods are included as supplementary material (Supplementary 1).

Briefly, 4,6-diamidino-2-phenylindole (DAPI) staining bacteria and total fungal hyphal length in the organic samples were enumerated microscopically.

DNA was extracted from $50 \mathrm{mg}$ of humus. The internal transcribed spacer (ITS) region of fungal ribosome-encoding genes and parts of the $16 \mathrm{~S}$ region of bacterial ribosome-encoding genes were PCR amplified. PCR products were pooled within treatments and cloned into Escherichia coli, resulting in four clone libraries (two sampling times $\times$ two treatments) each for fungi and bacteria. From each clone library, 48 clones were picked, and the amplicon inserts were re-amplified and sequenced. Sequences were clustered, allowing 1\% dissimilarity within clusters, and taxonomic affiliations were assigned based on phylogenetic relationships to reference sequences (Supplementary 2 and 3).

The fungal community composition in each sample was analysed by terminal restriction fragment length polymorphism (T-RFLP) based on polymorphisms in the ITS region. T-RFLP peaks in profiles obtained from humus samples were assigned to fungal taxa by comparisons with T-RFLP patterns obtained from cloned and identified genotypes (Lindahl et al., 2007). For each sample, the relative contribution of fungal taxa to the total community was estimated as the fluorescence of their associated T-RFLP peaks divided by the integrated fluorescence of the entire T-RFLP profile.

On the basis of the sequences obtained from cloned ITS amplicons, primers were designed to specifically amplify a group of taxa within the fungal order Helotiales with sequence affinity to 
Leptodontidium anamorphs (Supplementary 3). After testing the primers for specificity, the absolute amount of Leptodontidium ITS template in the DNA extracts was estimated by quantitative PCR.

Activities of extracellular enzymes were assessed in humus extracts produced by adding $1 \mathrm{~g}$ of soil to $3 \mathrm{ml}$ of deionised water and shaking vigorously for $60 \mathrm{~min}$ at $4{ }^{\circ} \mathrm{C}$. After centrifugation and filtration of the extracts, activities of laccases, cellulases, manganese peroxidases and $\mathrm{N}$-acetylglucosaminidases (NAGs) were estimated, using colorogenic or fluorogenic substrates.

\section{Statistical analysis}

Effects on microbial biomass estimates, amounts of extracted DNA, enzyme activities and Leptodontidium abundance values were tested using two-way analysis of variance (ANOVA), with root severing and sampling time as explaining variables. Hyphal lengths, cellulase activities and Leptodontidium abundance values were log transformed before analysis, to meet the assumptions of ANOVA. The distribution of laccase and NAG activities did not meet the assumptions of ANOVA, and effects of root severing and sampling time were tested independently using Mann-Whitney $U$-tests. Linear regression was used to test for possible correlations between microbial biomass estimates and the amount of extracted DNA or log-transformed enzyme activities. Possible correlations between Leptodontidium abundance and hyphal length or enzyme activities were also tested by linear regression.

The distributions of cloned amplicons across bacterial phyla and across fungal orders were tested for independency in relation to root severing and sampling time, using $\chi^{2}$ tests. Groups represented by few clones were merged, so that no events had expected frequencies lower than 4. Differences between samples in fungal community composition, as analysed by T-RFLP, were represented graphically by correspondence analysis (terBraak, 1986) using CANOCO version 4.5 for Windows (Microcomputer Power, Ithaca, NY, USA). The effects of root severing and sampling time on fungal community composition were tested for statistical significance separately by canonical correspondence analysis followed by Monte Carlo tests. The analyses were repeated with taxon abundances merged within genera. In two samples, the fungal communities were completely dominated by Phellodon niger and Luellia recondita, which were absent in all other samples. These two samples, which deviated strongly in the ordination analyses and also differed in their very thin humus layers, were excluded.

\section{Results}

Microbial biomass and enzyme activities

Average hyphal length more than doubled after root severing $(P<0.0001)$ regardless of sampling time
(Figure 1a). Neither bacterial counts, nor DNA amounts were significantly affected by root severing (Figures $1 \mathrm{~b}$ and $\mathrm{c}$ ). The total amounts of extracted DNA were higher $(P=0.048)$ at the 14 th-day sampling than at the 5th-day sampling, and there was a similar, nonsignificant trend for bacterial counts $(P=0.057)$. The total amounts of extracted DNA correlated with bacterial counts $(P=0.011)$ but not with hyphal lengths.

Laccase activities increased after root severing by an order of magnitude $(P<0.0001)$ regardless of sampling time (Figure 1e), and were positively correlated with hyphal lengths $(P<0.0001)$. When the root severing was included as an explaining variable, however, the correlation was reduced to a nonsignificant trend $(P=0.08)$. Cellulase activities were on average fivefold higher after root severing $(P=0.024)$, but only at the 5th-day sampling (interaction $P=0.023$ ). At the 14 th-day sampling, cellulase activities were similar in both treatments and intermediate between those of disturbed and undisturbed 5th-day samples (Figure 1f). Average NAG activity was sixfold higher after root severing, but the difference was not statistically significant $(P=0.08)$, because of the large variation between samples (Figure 1h). Average manganese peroxidase activities were similar regardless of root severing or sampling time (Figure 1g).

\section{Clone libraries}

From the clone libraries of bacterial $16 \mathrm{~S}$ amplicons, 169 high-quality sequences were obtained. The sequences are deposited at NCBI (National Center for Biotechnology Information; www.ncbi.nlm.nih.gov) under accession numbers GU558922-GU559073. Eleven sequences that were attributed to plant chloroplast DNA (which is also amplified by general 16S primers) and six sequences that were identified as PCR chimeras were removed from further analyses. Five sequences could not be assigned to phyla. Actinobacteria dominated among the cloned bacterial $16 \mathrm{~S}$ sequences followed by Alphaproteobacteria, Gammaproteobacteria, Acidobacteria and Planctomycetes (Figure 2a). The distribution of $16 \mathrm{~S}$ clones across phyla was not significantly affected by root severing $(P=0.57)$ or sampling time $(P=0.30)$.

From the clone libraries of fungal ITS amplicons, 163 high-quality sequences were obtained, representing 53 genotypes (a single sequence was dismissed as a PCR chimera). The sequences are deposited at NCBI under accession numbers GU559074-GU559126. Five sequences (each represented by a single clone) could not be assigned to orders with confidence. Agaricales (mainly Cortinarius spp.) was the dominant order followed by Helotiales and Chaetothyriales (Capronia spp.) (Figure 2b). The distribution of ITS clones across orders was found to be significantly affected by root severing $(P<0.001)$ but not by sampling time $(P=0.21)$. The proportion of Agaricales (Cortinarius) 

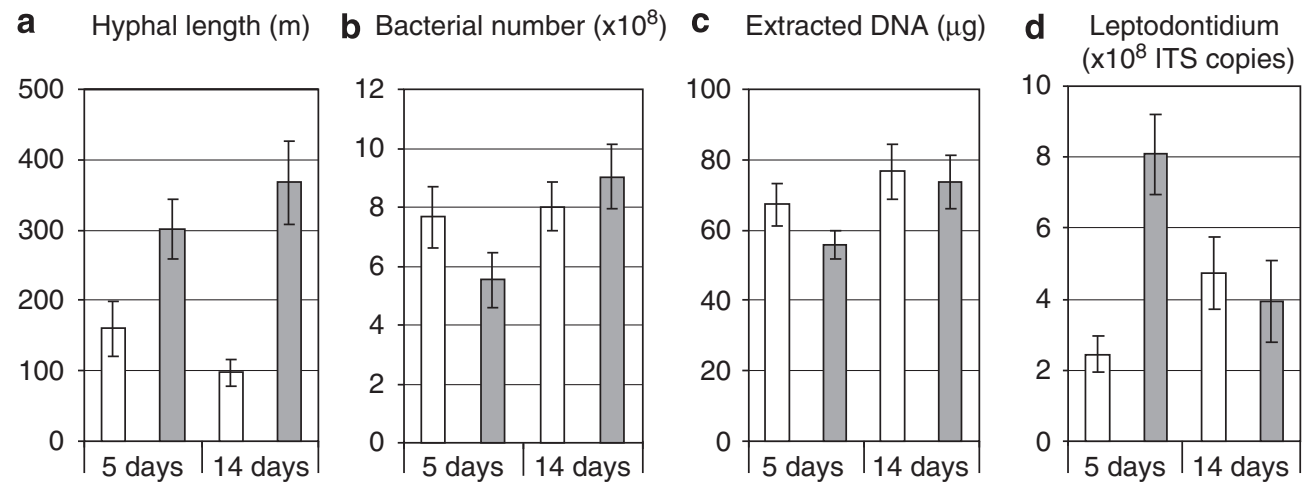

e Laccase activity $(\mathrm{mU})$

f Cellulase activity $(\mathrm{mU})$

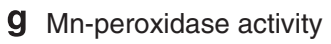

h NAG activity (mU)
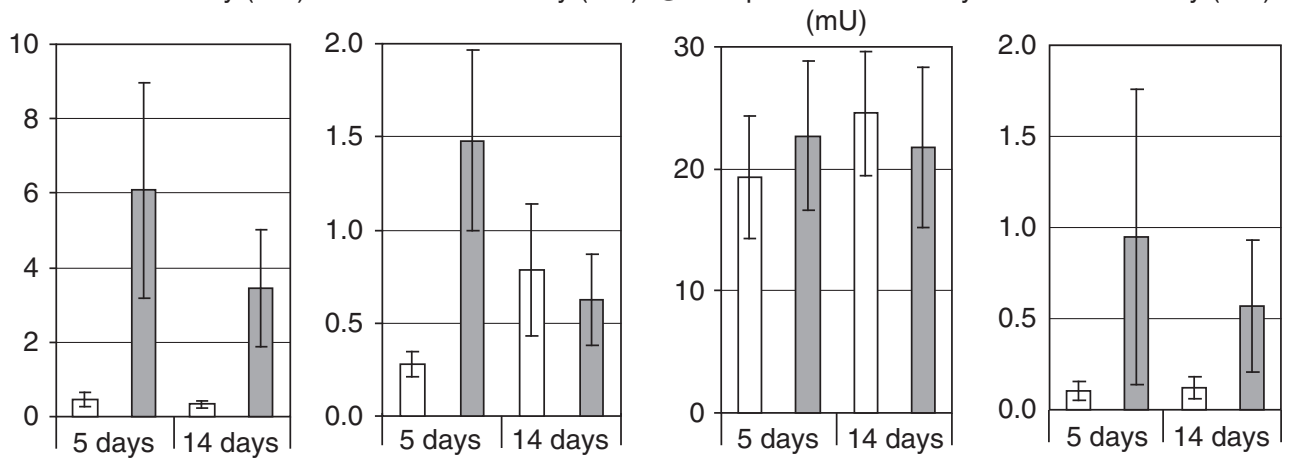

Figure 1 Estimates of microbial biomass (a-d) and enzyme activities (e-h) in humus samples from a Pinus sylvestris forest. Nondisturbed samples (open bars) are compared with samples in which root connections were severed (shaded bars) 5 or 14 days before collection. All estimates are reported per gram dry weight of humus with error bars representing \pm 1 s.e.

clones decreased after root severing, whereas the proportion of Helotiales and Chaetothyriales (Capronia) clones increased. At the 5th day sampling, the proportion of clones attributed well-established mycorrhizal taxa was $87 \%$ in non-disturbed samples but only $54 \%$ in samples with severed roots. The corresponding figures for the 14 th day sampling were $67 \%$ and $35 \%$.

Terminal restriction fragment length polymorphism The entire set of reference T-RFLP patterns derived from the sequenced clones contained six groups of 2-4 genotypes and 34 single genotypes, which all yielded unique T-RFLP peaks from at least some of the primer-enzyme combinations. Of these, 22 were identified among the T-RFLP profiles from the soil samples, whereas 18 genotypes failed to reach the cut-off threshold $5 \%$ of the height of the strongest peak in the sample) in one or more of the primerenzyme combinations and were recorded as absent. Taxon abundances according to their average share of the T-RFLP fluorescence correlated reasonably well with the representation of taxa in the clone libraries $\left(R^{2}=0.82\right)$. Four additional taxa were detected in the samples as T-RFLP patterns, although they were not present among the sequenced clones. The T-RFLP patterns of these taxa were obtained from sequenced clones from a previous study at the same site (Lindahl et al., 2007) and belong to a subphylum within the Ascomycota, hitherto described on the basis of DNA sequences only (clone group I; Porter et al., 2008). Considering the high abundance of these taxa in the T-RFLP profiles; on average $14 \%$ of the fluorescence, it is surprising that they did not occur among the sequenced clones. The identified taxa accounted for $30-93 \%$ (average $65 \%$ ) of the total fluorescence in the T-RFLP profiles, the rest being attributed to genotypes with low abundance, together with erroneous non-ITS PCR products (Figure 3).

In the correspondence analysis, approximately half of the samples with severed roots were found outside the space occupied by the early, nondisturbed samples, indicating a difference in fungal community composition. Some of the undisturbed samples from the late sampling also deviated in community composition in the same direction (Figure 4). Canonical analysis indicated that the effect of root severing on community composition was marginally insignificant when analysed at the species level $(P=0.062)$, but clearly significant when taxa were merged within genera $(P=0.012)$. There was no significant effect of sampling time on community composition $(P=0.15)$.

In the following presentation, average taxon abundances are presented as fractions of the total identified community, assuming that most of the 


\section{UNDISTURBED SAMPLES}

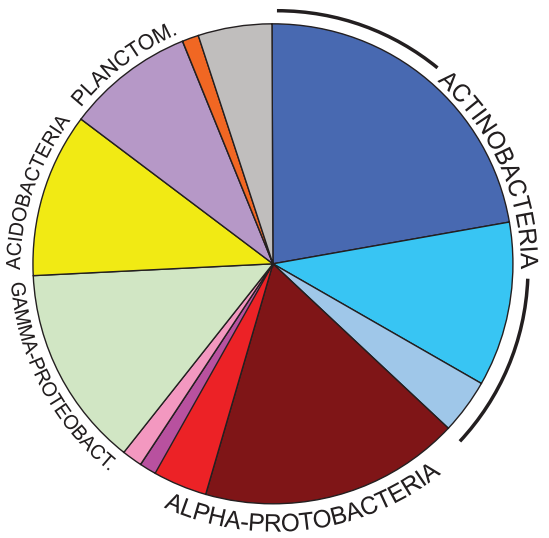

b
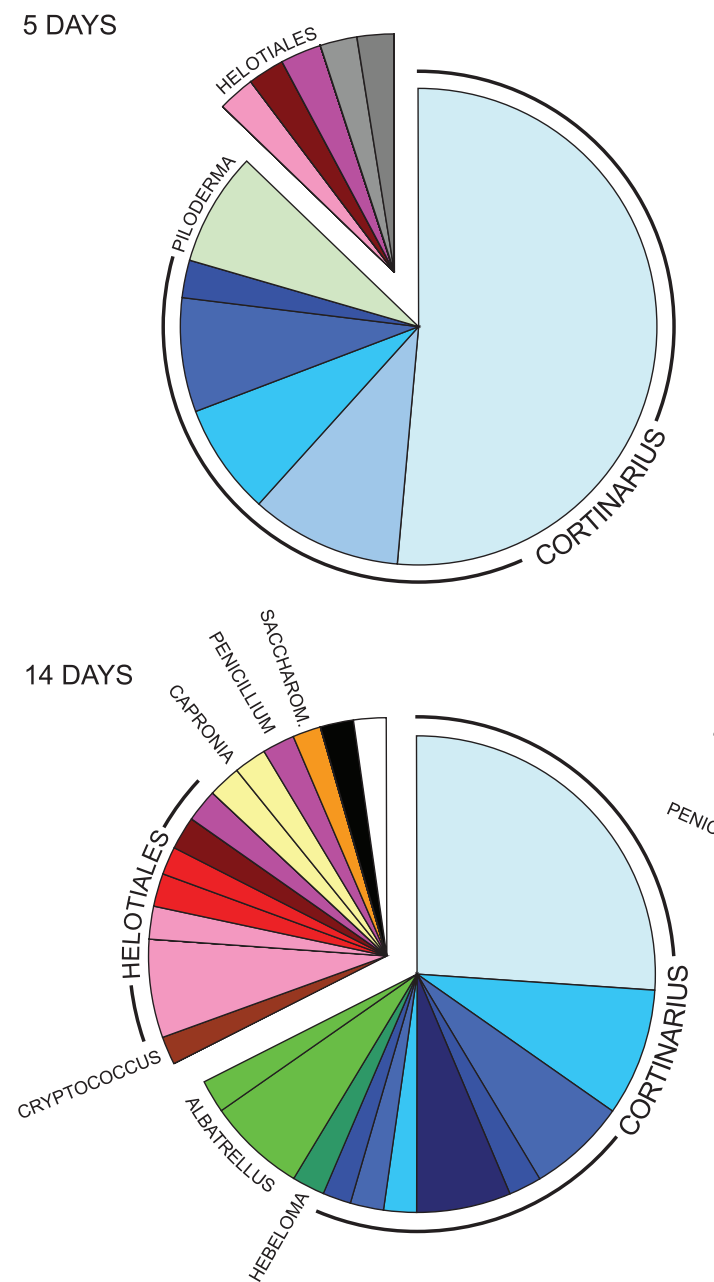

SAMPLES WITH SEVERED ROOTS

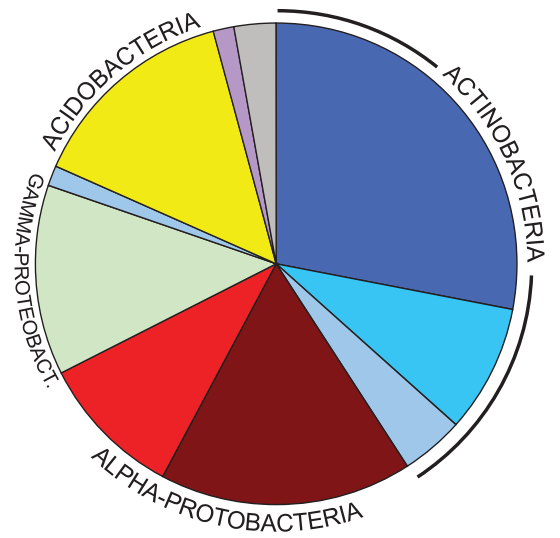

- Actinobacteridae

$\square$ Acidimicrobidae

$\square$ Rubrobacteridae

- Rhizobiales

- Acetobacteraceae

- Caulobacterales

$\square$ Sphingomonadales

$\square$ Gamma proteobacteria

$\square$ Delta proteobacteria

$\square$ Acidobacteria

$\square$ Planctomycetes

$\square$ Verrucomicrobiae

$\square$ UnID

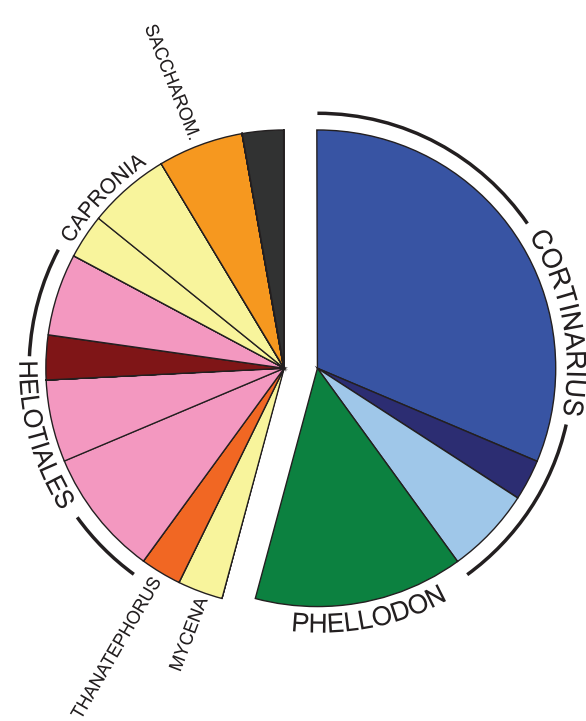

$\square$ Cortinarius caperatus $\square$ Cortinarius umbrinolens

『ে $\square$ Cortinarius malachius

$\underset{ \pm}{*}$ Cortinarius obtusus

$\bar{\pi} \square$ Cortinarius traganus

N Cortinarius sp. 3

든 Cortinarius brunneus

¿ Cortinarius armeniacus

¿ Cortinarius biformis

Cortinarius semisanguineus

$\square$ Hebeloma sp. 41

口 Phellodon niger

$\square$ Albatrellus sp.

$\square$ Piloderma sphaerosporum

$\square$ Mycena sp.

$\square$ Luellia recondita

- Thanatephorus cucumeris

- Cryptococcus sp.

$\square$ Leptodontidium $\mathrm{C}$

$\square$ Leptodontidium $\mathrm{F}$

- Rhizoscyphus ericae

- Rhizoscyphus complex

- Helotiales E

口 Helotiales 14

口 Helotiales 17

- Helotiales 47

$\square$ Capronia D

- Penicillium spinulosum

$\square$ Saccharomycotina

$\square$ Saccharomycotina

- Mortierella sp.

- Mortierella humilis

$\square$ Mortierella sp.

$\square$ Mortierella sp.

$\square$ UnID

$\square$ UnID

- UnID

- UnID

Figure 2 Distribution of (a) bacterial 16S clones and (b) fungal ITS clones across bacterial groups and fungal species in humus samples from a Pinus sylvestris forest where some samples had root connections severed 5 or 14 days before collection. Bacterial 16S data from the two sampling times were merged. Ectomycorrhizal fungal taxa are represented by blue-green colours, while other functional groups of fungi are shown in yellow-red-brown.

unidentified fluorescence in the T-RFLP analyses may be attributed to erroneous non-ITS PCR products. According to the T-RFLP analysis, Cortinarius on average constituted $69 \%$ of the fungal community in non-disturbed samples, but only $33 \%$ after root severing at the 5th day sampling. The corresponding figures for the 14th day sampling were $48 \%$ and $25 \%$. The most common species 


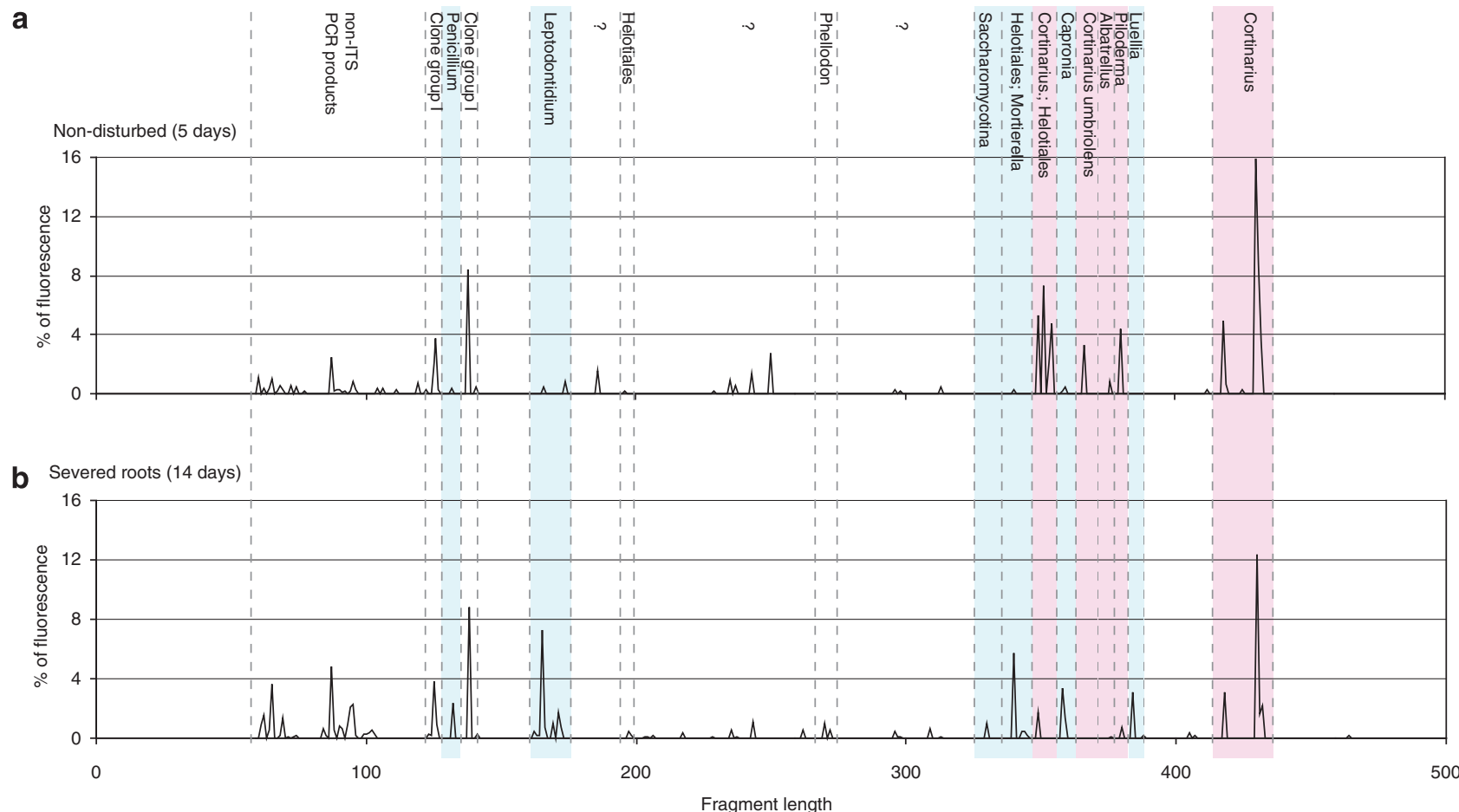

Figure 3 T-RFLP profiles based on the average fluorescence associated with different fragment lengths. The profiles were obtained from humus samples from a Pinus sylvestris forest and represent (a) non-disturbed samples (b) samples collected 14 days after severing of roots. The profiles represent fungal ITS amplicons after digestion with the restriction enzyme CfoI, with the ITS1f primer fluorescently labelled. Taxa that decrease in relative abundance in response to root severing are indicated by red shading, whereas taxa that increase in relative abundance after root severing are indicated by green shading.

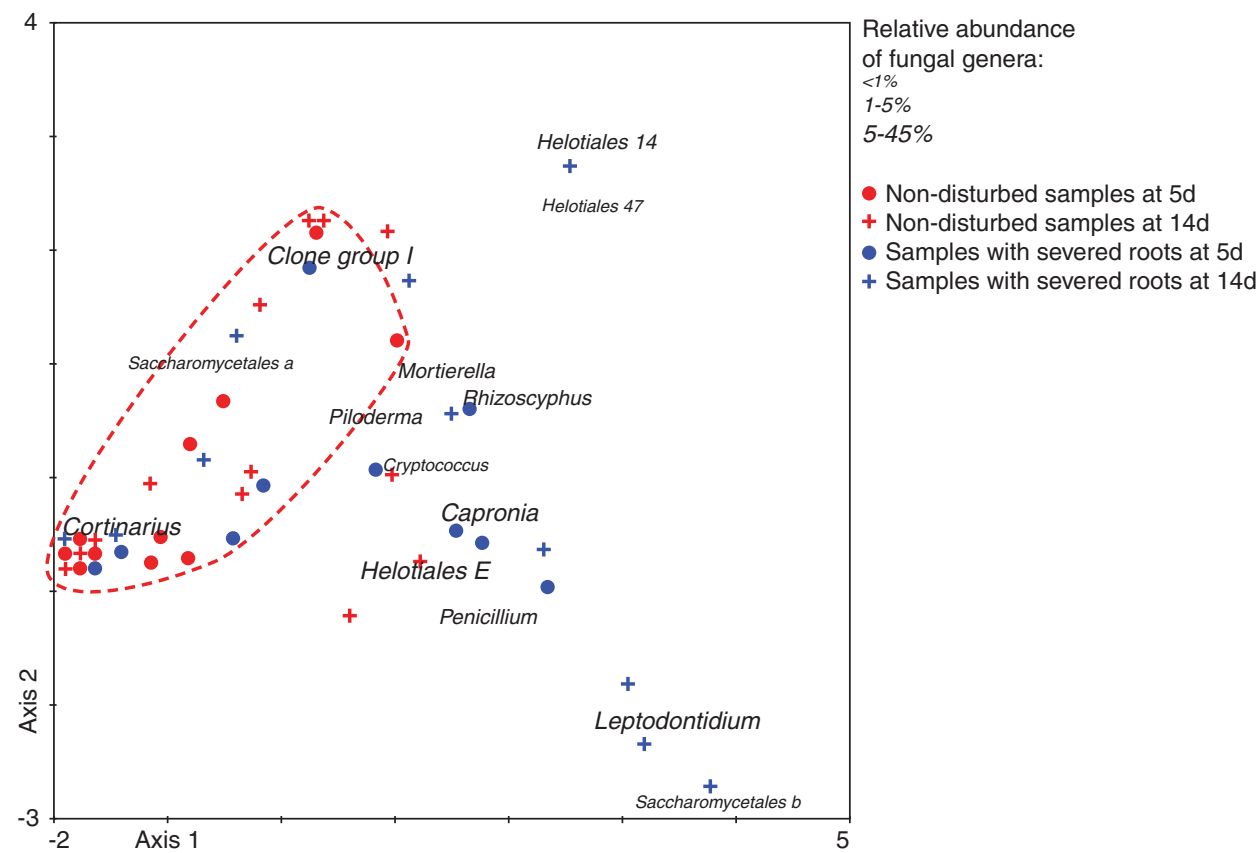

Figure 4 Correspondence analysis based on the relative abundances of fungal genera in humus samples from a Pinus sylvestris forest, as estimated by T-RFLP. Axes 1 and 2 together account for $45 \%$ of the total inertia of the data.

(at the start of the experiment) was Cortinarius caperatus, which constituted $36 \%$ of non-disturbed communities, but only $3 \%$ after root severing at the 5th day sampling. At 14 days, however, it accounted for $16-17 \%$ of both disturbed and undisturbed communities. Taxa within the Helotiales constituted 
$6 \%$ of non-disturbed communities, but $21 \%$ after root severing ( $13 \%$ and $30 \%$ after 14 days). The same pattern was observed for other ascomycetes; Capronia species constituted 1\% of non-disturbed communities, but $10 \%$ after root severing $(2 \%$ and $6 \%$ at 14 days) and Penicillium spinulosum was not detected in non-disturbed samples, but constituted $6 \%$ in samples with severed roots $(4 \%$ in both treatments at 14 days). Mortierella species were not detected in non-disturbed samples but constituted $1 \%$ of the community 5 days after root severing and $4 \%$ after 14 days. The ascomycetous clone group I seemed unaffected by root severing, constituting $16 \%$ in undisturbed samples and $14 \%$ after root severing (32\% and $19 \%$ at 14 days) (Figure 3).

\section{Quantitative PCR on Leptodontidium species}

The primers we used specifically amplified taxa within the Leptodontidium complex. Taken together, the two different reverse primers amplified all cloned ITS products within the group without overlap in target range. PCR efficiencies ranged between $74 \%$ and $79 \%$ and inhibition ranged between $0 \%$ and $70 \%$ with an average of $18 \%$.

The numbers of Leptodontidium ITS copies per gram humus (results of both reverse primers added) were significantly higher after root severing $(P=0.025)$ but not generally affected by sampling occasion $(P=0.38)$. The interaction between root disturbance and sampling time was, however, highly significant $(P=0.001)$. At 5 days after root severing, the numbers of Leptodontidium ITS copies were, on average, more than three times higher in samples with severed roots compared with undisturbed samples. After 14 days, the levels had decreased in samples with severed roots and increased in non-disturbed samples and were similar in the two treatments (Figure 1d). The amount of Leptodontidium DNA in the humus correlated positively with cellulase activity $(P<0.0001)$, and the relationship remained when root severing, sampling time and their interaction were included as explaining variables.

\section{Discussion}

We hypothesised that a rapid decline in the abundance of living mycorrhizal mycelium, in response to root severing, would lead to increased abundance of opportunistic saprotrophs. Rapid growth of fungi occurred within 5 days of root severing, as indicated by the doubled density of microscopically distinguishable fungal hyphae in the humus (Figure 1a). The results of the molecular analyses indicate that certain groups of ascomycetes within the order Helotiales and the genera Capronia and Penicillium, together with mucoromycetes (Mortierella species), increased their share of the fungal DNA pool (Figures 2b, 3 and 4), and it seems likely that the increased hyphal densities may be attributed to these groups. Quantitative PCR confirmed that the amount of Leptodontidium DNA 5 days after root disruption had increased compared with controls, not only in relative terms, but also in absolute abundance (Figure 1d). After 14 days, the relative abundance of Leptodontidium remained high in root-severed samples, but the absolute amount had decreased to half of the level detected at 5 days and to a similar level as in the controls. Between 5 and 14 days, it thus seems as if the total fungal DNA pool decreased, implying that the relative decrease of ectomycorrhizal taxa corresponds to an even more dramatic decline in absolute terms. The increasing share of other fungi in the community during this period has to be considered in relation to the mycorrhizal decline.

Root disruption, thus, seemed to cause a major reduction in the amount of ectomycorrhizal DNA concomitant with a pulse of hyphal production by certain ascomycetes and, later, also mucoromycetes. The disturbance made new resources available in the form of senescing mycorrhizal mycelium, which may have been used by the proliferating, opportunistic saprotrophs. In addition, root disruption may have relaxed mycorrhizal interference competition, allowing free-living saprotrophs to increase in abundance. This field-based finding is in accordance with previous observations of mycorrhizal interference competition in laboratory microcosms (Lindahl et al., 1999, 2001, 2002; Werner et al., 2002). The relative importance of reduced mycorrhizal interference and substrate enrichment is, however, difficult to establish. These concepts overlap in that the living mycorrhizal mycelium constitutes a potential resource for saprotrophs and parasites, which is defended by the mycorrhizal fungi through antagonistic interactions. This study addressed short-term effects of disrupted translocation. In a longer term perspective, tree girdling has been shown to increase the relative abundance of nonectomycorrhizal fungi (Yarwood et al., 2009), and increased decomposition rates have been observed in trenched plots (Gadgil and Gadgil, 1971). However, long-term effects on the absolute abundance and activities of saprotrophs remain uncertain.

PCR products with 99-100\% sequence similarity to the most commonly detected Leptodontidium genotype have also been amplified from coniferous forest soils in Canada, Alaska and eastern USA, as well as from hair roots of ericaceous shrubs in Scotland (Bougoure et al., 2007). The ecology of Capronia species is uncertain; pathogenic, mycoparasitic as well as lichen forming taxa have been described, but their capacity as primary saprotrophs of plant litter has been questioned (Untereiner and Malloch, 1999). Some Capronia strains have been confirmed to form mycorrhiza-like structures within roots of ericaceous shrubs (Allen et al., 2003). It is not impossible that ericoid symbionts could have been favoured by root disruption, as Vaccinium 
plants were often rooted inside isolated cores. However, the rapid decline of the Leptodontidium group during the later phase of the experiment, together with the positive correlation with cellulase activity and the relative rarity of the group under undisturbed conditions, suggest that this group consists of free-living opportunists. One of the more common Mortierella genotypes was assigned to $M$. humilis, which has been shown to degrade cellulose when colonising straw (Varnaite et al., 2008). None of the species that responded positively to root severing was detected in decomposing needles collected at the same research site (Lindahl et al., 2007), indicating that they are not regular litter saprotrophs.

The high abundance of Actinobacteria and Acidobacteria, in combination with the absence of Betaproteobacteria and Bacteriodetes, indicates a bacterial community adapted to low carbon availability (Fierer et al., 2007). In contrast to the dramatic responses observed in the fungal community, the bacterial community did not respond significantly to root disruption (Figures $1 \mathrm{~b}$ and 2a). A plausible explanation is that the saprotrophic fungi, which prospered in response to mycorrhizal senescence, suppressed the bacterial community, replacing the mycorrhizal fungi as dominants. Antagonism against bacteria is well established for many ascomycetes (Gloer, 2007).

The shifts in the fungal community were associated with increased cellulase, laccase and NAG activities (Figures 1e-g), although the latter was highly variable between samples. Cellulase activity correlated with Leptodontidium abundance, suggesting a causal relationship. Increased activities of enzymes involved in hydrolysis and oxidation of organic substrates support the picture of a shift from a mycorrhizal community, independent of the need to acquire energy from dead organic matter, to a saprotrophic community, acquiring energy from the degradation of organic substrates through the action of extracellular enzymes. Laccases may be used to degrade phenolic compounds in organic matter, but are also frequently produced during competitive interactions between saprotrophic fungi (Baldrian, 2004). NAGs are enzymes involved in chitin degradation, and are produced at increased rates when fungi overgrow dead mycelium of other fungi (Lindahl and Finlay, 2006). The trend of increased NAG activity, in response to root severing, supports the idea that dead, mycorrhizal mycelium could be an important substrate for the responding saprotrophs (Lindahl et al., 2001). However, increased cellulase activity indicates that plant-derived organic matter was also used. Dying roots could, potentially, constitute a new substrate in the disturbed samples, although the decline in cellulase activity after 14 days suggests that other, more rapidly depleted substrates were mainly used. The activity of Mn-peroxidases, which are enzymes capable of oxidation of the most recalcitrant com- pounds in soil, such as large humic complexes and lignin, did not change in response to root severing (Figure 1f). The lack of increase in peroxidase activity is consistent with the view that these enzymes are primarily produced by basidiomycetes, and that the responding ascomycetes and mucoromycetes act mainly as opportunists, using more easily degradable substrates. It has been suggested that ectomycorrhizal fungi may be the main decomposers of humus, as they possess Mn-peroxidase genes (Bödeker et al., 2009) and are the only basidiomycetes that occur abundantly in humus (Lindahl et al., 2007). This hypothesis is supported by the relatively high Mn-peroxidase activities observed in the undisturbed samples, in which mycorrhizal fungi dominated the community, but disagrees with the sustained activities in spite of root disruption. The persistently high Mn-peroxidase activities after root severing may indicate a slow turnover rate of these enzymes in the humus.

After 14 days, some of the control samples showed resemblance to root-severed samples, both with respect to fungal community composition (Figures 1d, 2b and 4) and raised cellulase activities (Figure 1f). Possibly, trampling during establishment of the experiment and the first sample collection, together with the disruption of roots associated with collection of other samples, also caused some disturbance of the fungal community in the control samples. After 14 days, Cortinarius caperatus had increased in abundance in root-severed samples relative to a very low prevalence at 5 days. This could be explained by re-colonisation of the cores from below, because this species was present in the mineral soil (Lindahl et al., 2007).

Litter saprotrophs in the boreal forest are nitrogen limited (Boberg et al., 2008) and little net release of nitrogen seems to take place during the early, saprotrophic stages of decomposition (Berg et al., 1982). Instead, nutrients are recycled to plants from more degraded litter and humus (Melillo et al., 1989; Lindahl et al., 2007). As previously shown, fungal communities in undisturbed humus layers of boreal forests are dominated by mycorrhizal fungi, and nutrients are likely to be recycled to plants directly by mycorrhizal fungi rather than via mineralisation by saprotrophs (Lindahl et al., 2002, 2007; Schimel and Bennet, 2004). However, disturbance of translocation pathways from leaves, via roots to mycorrhizal mycelium reduces the dominance of mycorrhizal fungi and permits free-living fungi to proliferate in the humus. The opportunistic saprotrophs presumably live on dead mycorrhizal mycelium, as well as on other compounds that become easily available because of the disturbance. Having no access to other, external carbon sources, such as living roots or fresh litter, the opportunists are more likely to experience carbon limitation and release nutrients in an inorganic form. We have, thus, shown a plausible mechanism behind the raised levels of inorganic nitrogen that have been observed 
in association with disturbance in boreal forests (Siira-Pietikäinen et al., 2001; Carmosini et al., 2003; Lavoie and Bradley, 2003; Sulkava and Huhta, 2003; Lapointe et al., 2005; Piirainen et al., 2007). However, because of the potential removal of $\mathrm{NH}_{4}^{+}$ by roots in the undisturbed systems, we were not able to directly address the question of whether the changes in fungal community composition actually led to increased $\mathrm{N}$ mineralisation rates. This problem highlights the difficulties in measuring mineralisation rates in systems that are sensitive to root disruption. In fact, our results cast a shadow of doubt over all methods used to study microbial processes in isolated forest soil samples, in which root connections have been severed. Clearly, such measurements are conducted on a microbial community that is functionally very different from that of the undisturbed soil. By excluding mycorrhizal fungi, measurements are likely to underestimate microbial respiration and growth. In contrast, because of triggering of opportunistic saprotrophs, nutrient mineralisation rates are likely to be vastly overestimated.

The functional shift in the microbial community shown in this study was related to changes in relative dominance of functional groups of fungi, highlighting the insufficient resolution of methods that target all fungi as a single functional entity. Molecular community analyses provide the resolution required to identify species and functional groups. Methodological development in molecular fungal ecology is currently undergoing a boom (Hibbett et al., 2009), and in combination with careful field manipulations and measurements of environmental and functional parameters, such as elemental concentrations and enzyme activities. DNA-based methods may enable us to elucidate environmental drivers of fungal community assembly, as well as the functional roles of fungal communities in ecosystems. Our results suggest that repression of free-living fungi by mycorrhizal fungi may be a significant factor in shaping fungal communities. Disruption of carbon translocation pathways because of natural or anthropogenic disturbances may induce dramatic shifts in fungal community composition, potentially reducing nutrient retention in fungal mycelial networks.

\section{Acknowledgements}

Financial support from The Swedish Research Council for Environment, Agricultural Sciences and Spatial Planning (FORMAS) is gratefully acknowledged. We also thank Katarina Ihrmark, for valuable collaboration during method development, Fredrik Heyman and Wiecher Smant for assistance during field work and laboratory analyses, respectively, and Karina Clemmensen, for critical reading of the paper.

\section{References}

Allen TR, Millar T, Berch SM, Berbee ML. (2003). Culturing and direct DNA extraction find different fungi from the same ericoid mycorrhizal roots. New Phytol 160: 255-272.

Baldrian P. (2004). Increase of laccase activity during interspecific interactions of white-rot fungi. FEMS Microbiol Ecol 50: 245-253.

Berg B, Hannus K, Popoff T, Theander O. (1982). Changes in organic chemical components of needle litter during decomposition. Long-term decomposition in a Scots pine forest I. Can J Bot 60: 1310-1319.

Boberg J, Finlay R, Stenlid J, Näsholm T, Lindahl BD. (2008). Glucose and ammonium additions affect needle decomposition and carbon allocation by the litter degrading fungus. Mycena epipterygia Soil Biol Biochem 40: 995-999.

Boddy L. (1999). Saprotrophic cord-forming fungi: meeting the challenge of heterogeneous environments. Mycologia 91: 13-32.

Bödeker ITM, Nygren CMR, Taylor AFS, Olson Å, Lindahl BD. (2009). ClassII peroxidase encoding genes are present in a wide phylogenetic range of ectomycorrhizal fungi. ISME J 3: 1387-1395.

Bougoure DS, Parkin PI, Cairney JWG, Alexander IJ, Anderson IC. (2007). Diversity of fungi in hair roots of Ericaceae varies along a vegetation gradient. Mol Ecol 16: 4624-4636.

terBraak CJF. (1986). Canonical correspondence analysis: a new eigenvector technique for multivariate direct gradient analysis. Ecology 67: 1167-1179.

Brant JB, Myrold DD, Sulzman EW. (2006). Root controls on soil microbial community structure in forest soils. Oecologia 148: 650-659.

Butenschoen O, Poll C, Langel R, Kandeler E, Marhan S, Scheu S. (2007). Endogeic earthworms alter carbon translocation by fungi at the soil-litter interface. Soil Biol Biochem 39: 2854-2864.

Carmosini N, Devito KJ, Prepas EE. (2003). Net nitrogen mineralization and nitrification in trembling aspen forest soils on the Boreal Plain. Can J Forest Res 33: 2262-2268.

DeLuca TH, Keeney DR, McCarty GW. (1992). Effect of freeze-thaw events on mineralization of soil nitrogen. Biol Fert Soils 14: 116-120.

Fierer N, Bradford MA, Jackson RB. (2007). Toward an ecological classification of soil bacteria. Ecology 88: 1354-1364.

Finlay RD, Read DJ. (1986). The structure and function of the vegetative mycelium of ectomycorrhizal plants: I. Translocation of ${ }^{14} \mathrm{C}$-labelled carbon between plants interconnected by a common mycelium. New Phytol 103: 143-156.

Gadgil RL, Gadgil PD. (1971). Mycorrhiza and litter decomposition. Nature 233: 133.

Gloer JB. (2007). Applications of fungal ecology in the search for new bioactive natural products. In: Kubicek CP, Druzhinina IS (eds). Environmental and Microbial Relationships, 2nd edn, The Mycota IV. SpringerVerlag: Berlin, pp 257-283.

Hibbett DS, Ohman A, Kirk PM. (2009). Fungal ecology catches fire. New Phytol 184: 279-282.

Högberg MN, Högberg P. (2002). Extramatrical ectomycorrhizal mycelium contributes one-third of microbial biomass and produces, together with associated roots, half the dissolved organic carbon in a forest soil. New Phytol 154: 791-795.

Lapointe B, Bradley RL, Shipley B. (2005). Mineral nitrogen and microbial dynamics in the forest floor of clearcut or partially harvested successional boreal forest stands. Plant Soil 271: 27-37. 
Lavoie M, Bradley RL. (2003). Short-term increases in relative nitrification rates due to trenching in forest floor and mineral soil horizons of different forest types. Plant Soil 252: 367-384.

Leake JR, Donnelly DP, Saunders EM, Boddy L, Read DJ. (2001). Rates and quantities of carbon flux to ectomycorrhizal mycelium following ${ }^{14} \mathrm{C}$ pulse labeling of Pinus sylvestris seedlings: effects of litter patches and interaction with a wood- decomposer fungus. Tree Physiol 21: 71-82.

Lindahl BD, Finlay RD. (2006). Activities of chitinolytic enzymes during primary and secondary colonisation of wood by wood degrading basidiomycetes. New Phytol 169: 389-397.

Lindahl BD, Finlay RD, Cairney JWG. (2005). Enzymatic activities of mycelia in mycorrhizal fungal communities. In: Dighton J, Oudemans P, White J (eds). The Fungal Community: Its Organization and Role in the Ecosystem. Taylor \& Francis: Boca Raton pp 331-348.

Lindahl BD, Ihrmark K, Boberg J, Trumbore SE, Högberg P, Stenlid J et al. (2007). Spatial separation of litter decomposition and mycorrhizal nitrogen uptake in a boreal forest. New Phytol 173: 611-620.

Lindahl BD, Olsson S. (2004). Fungal translocationcreating and responding to environmental heterogeneity. Mycologist 18: 79-88.

Lindahl B, Stenlid J, Finlay R. (2001). Effects of resource availability on mycelial interactions and ${ }^{32} \mathrm{P}$-transfer between a saprotrophic and an ectomycorrhizal fungus in soil microcosms. FEMS Microbiol Ecol 38: 43-52.

Lindahl B, Stenlid J, Olsson S, Finlay R. (1999). Translocation of ${ }^{32} \mathrm{P}$ between interacting mycelia of a wood decomposing fungus and ectomycorrhizal fungi in microcosm systems. New Phytol 144: 183-193.

Lindahl BD, Taylor A, Finlay R. (2002). Defining nutritional constraints on carbon cycling-towards a less 'phytocentric' perspective. Plant Soil 242: 123-135.

Melillo JM, Aber JD, Linkins AE, Ricca A, Fry B, Nadelhoffer KJ. (1989). Carbon and nitrogen dynamics along the decay continuum-plant litter to soil organic-matter. Plant Soil 115: 189-198.

O’Brien HE, Parrent JL, Jackson JA, Moncalvo J-M, Vilgalys R. (2005). Fungal community analysis by large-scale sequencing of environmental samples. Appl Environ Microb 71: 5544-5550.

Persson T. (1980). Structure and Function of Northern Coniferous Forests-An Ecosystem Study. Ecological Bulletins 32: Stockholm, Sweden.
Piirainen S, Finér L, Mannerkoski H, Starr M. (2007). Carbon, nitrogen and phosphorus leaching after site preparation at a boreal forest clear-cut area. Forest Ecol Manag 243: 10-18.

Porter TM, Schadt CW, Rizvi L, Martin AP, Schmidt SK, Scott-Denton L et al. (2008). Widespread occurrence and phylogenetic placement of a soil clone group adds a prominent new branch to the fungal tree of life. Mol Phylogenet Evol 6: 635-644.

Rosling A, Lindahl BD, Finlay RD. (2004). Carbon allocation to ectomycorrhizal roots and mycelium colonising different mineral substrates. New Phytol 162: 795-802.

Read DJ, Perez-Moreno J. (2003). Mycorrhizas and nutrient cycling in ecosystems-a journey towards relevance? New Phytol 157: 475-492.

Schimel JP, Bennet J. (2004). Nitrogen mineralization: challenges of a changing paradigm. Ecology 85: 591-602.

Siira-Pietikäinen A, Haimi J, Kanninen A, Pietikäinen J, Fritze H. (2001). Responses of decomposer community to root-isolation and addition of slash. Soil Biol Biochem 33: 1993-2004.

Subke J-A, Hahn V, Battipaglia G, Linder S, Buchmann N, Cotrufo MF. (2004). Feedback interactions between needle litter decomposition and rhizosphere activity. Oecologia 139: 551-559.

Sulkava P, Huhta V. (2003). Effects of hard frost and freezethaw cycles on decomposer communities and $\mathrm{N}$ mineralisation in boreal forest soil. Appl Soil Ecol 22: 225-239.

Untereiner WA, Malloch D. (1999). Patterns of substrate utilization in species of Capronia and allied black yeasts: ecological and taxonomic implications. Мyсоlogia 91: 417-427.

Varnaitė R, Paškevičius A, Raudonienė V. (2008). Cellulose degradation in rye straw by micromycetes and their complexes. Ekologija 54: 29-31.

Werner A, Zadworny M, Idzikowska K. (2002). Interaction between Laccaria laccata and Trichoderma virens in co-culture and in the rhizosphere of Pinus sylvestris grown in vitro. Mycorrhiza 12: 139-145.

Yarwood SA, Myrold DD, Högberg MN. (2009). Termination of belowground $\mathrm{C}$ allocation by trees alters soil fungal and bacterial communities in a boreal forest. FEMS Microbiol Ecol 70: 151-162.

Yavitt JB, Fahey TJ. (1984). An experimental analysis of solution chemistry in a Lodgepole pine forest floor. Oikos 43: 222-234.

Supplementary Information accompanies the paper on The ISME Journal website (http://www.nature.com/ismej) 